\title{
Pressure Cycling Technology-assisted Protein Digestion for Efficient Proteomic Analysis
}

\author{
Hyunsu Choi, Sang Kwang Lee, Kyung-Hoon Kwon, Jong Shin Yoo, Kelly Ji, ${ }^{\dagger}$ and Jin Young Kim* \\ Division of Mass Spectrometry, Korea Basic Science Institute, Ochang-eup, Cheongwon-gun, Chungbuk 363-883, Korea \\ ${ }^{*}$ E-mail: jinyoung@kbsi.re.kr \\ ${ }^{\dagger}$ CM Corporation Ltd., Room 501, Royal Plaza Building, 714, Suseo-dong, Gangnam-gu, Seoul 135-884, Korea \\ Received October 13, 2010, Accepted December 10, 2010
}

\begin{abstract}
In typical proteomic analysis, trypsin digestion is one of the most time-consuming steps. Conventional proteomic sample preparation methods use an overnight trypsin digestion method. In this study, we compared high-pressure cycling technology (PCT) during enzyme digestion for proteome analysis to the conventional method. We examined the effect of PCT on enzyme activity at temperatures of 25,37 , and $50{ }^{\circ} \mathrm{C}$. Although a fast digestion $(1 \mathrm{~h})$ was used for the standard protein mixture analysis, the PCT-assisted method with urea showed better results for protein sequence coverage and the number of peptides identified compared with the conventional method. There was no significant difference between temperatures for PCT-assisted digestion; however, we selected PCT-assisted digestion with urea at $25^{\circ} \mathrm{C}$ as an optimized method for fast enzyme digestion, based on peptide carbamylation at these conditions. The optimized method was used for stem cell proteome analysis. We identified 233, 264 and 137 proteins using the conventional method with urea at $37^{\circ} \mathrm{C}$ for $16 \mathrm{~h}$, the PCT-assisted digestion with urea at $25^{\circ} \mathrm{C}$ for $1 \mathrm{~h}$, and the non-PCT-assisted digestion with urea at $25^{\circ} \mathrm{C}$ for $1 \mathrm{~h}$, respectively. A comparison of these results suggests that PCT enhanced the enzyme digestion by permitting better access to cleavage sites on the proteins.
\end{abstract}

Key Words: Fast digestion, Pressure cycling technology (PCT), Enzyme activity, Stem cell proteome analysis

\section{Introduction}

Mass spectrometry (MS)-based proteomics is a powerful technique for characterizing individual proteins or very complex protein mixtures, such as whole cell lysates. The integration of MS instrumentation, ${ }^{1-3}$ multidimensional chromatographic separations, ${ }^{4}$ and computational data analysis ${ }^{5}$ has resulted in increasingly fast proteomics analyses. Consequently, MS-based multidimensional high-throughput analysis being of universal method has provided for proteomic profiling in cell, biological fluids, and tissues, as well as unveiling biological functions and their targeted metabolism.

Sample preparation has become a significant bottleneck in the high-throughput proteomics pipeline. Conventional strategies are indispensably concomitant with enzymatic digestion of biological samples either in solution or from gel spots after polyacrylamide gel electrophoresis (PAGE). ${ }^{6}$ In both of these strategies, the enzymatic digestion of the proteins is the most time-consuming step.

The enzymatic digestion of proteins has conventionally been performed in a buffered medium over a defined length of time, generally overnight $(\sim 12 \mathrm{~h})$. Successful enzyme digestion results in well digested peptides which are completely and accurately cleaved at expected sites, by allowing the enzymes to efficiently access the reactive amino acid cleavage sites. Such enzymatic reactions depend strongly on experimental factors, including temperature, buffer, $\mathrm{pH}$ range, and the enzyme-to-substrate ratio. $^{6}$

A means of denaturing proteins to allow enzymes to access the active cleavage sites on the proteins is still necessary since enzymatic activity is dependent on how the active cleavage sites upon amino acids of proteins are effectively exposed. It has been achieved conventionally by using a chemical denaturant, such as urea. ${ }^{7}$ However, the use of chemical denaturants can present challenges, including unexpected modification of proteins or peptides, inactivation of enzyme activity, or incompatibility with downstream MS analysis. ${ }^{8}$

Several studies have reported that chemical denaturants can be replaced by solvent-assisted digestions. ${ }^{9}$ The use of mixedsolvent buffers containing various concentrations of organic solvents (e.g., methanol, acetonitrile, isopropanol) resulted in protein denaturing as well as enhanced solubility of hydrophobic proteins. ${ }^{10}$

More recently, alternative energy inputs such as microwave energy $^{11}$ or high-intensity focused ultrasound ${ }^{12}$ have been applied to digestions to further increase enzyme reaction rates. These approaches reduced the time required for digestion to several minutes using microwave-assisted digestion and to $15-30 \mathrm{~s}$ using high-intensity focused ultrasound. They were useful for solution ${ }^{13}$ or in gel ${ }^{14}$ digestions and were shown to be applicable to complex protein mixtures. ${ }^{10}$

High pressure is another alternative energy that has been used to increase enzymatic activity. ${ }^{15}$ High pressure is thought to change the protein conformation and force the penetration of water molecules into the protein interior, especially into cavities, leading to denaturing of the protein. ${ }^{16}$

In this study, we used PCT, which uses alternating cycles of atmospheric and high pressure, up to tens of $\mathrm{kpsi}$ ( $1 \mathrm{kpsi}=6.895$ $\mathrm{MPa}) .{ }^{17}$ Recent studies have shown enhanced digestion speed using trypsin, chymotrypsin, and pepsin under pressure cycl- 
ing. ${ }^{18}$ Lopez-ferrer has reported that in-solution tryptic digestion of complex protein mixtures was achieved in less than $60 \mathrm{~s}$ using pressure cycling technology. ${ }^{6}$ Yang and Kim et al. published a simple and effective pressure-assisted method using a syringe. ${ }^{19}$ In their study, digestion efficiency was improved by applying $6 \mathrm{~atm}$ of pressure using a syringe, compared with digestion at atmospheric pressure.

In the study reported here, we examined the effect of PCT on enzyme activity at temperatures of 25,37 , and $50{ }^{\circ} \mathrm{C}$ with or without urea, and we compared the results with the conventional method. We also used PCT for human mesenchymal stem cell proteome analysis and evaluated the performance of PCT as a means of enhancing enzyme activity.

\section{Experimental}

Materials. Formic acid, ammonium bicarbonate, urea, dithiothreitol (DTT), iodoacetamide (IAA), $\alpha$-lactalbumin (bovine), alcohol dehydrogenase I (yeast), and fructose-bisphosphate aldolase A (rabbit) were purchased from Sigma-Aldrich (St. Louis, MO, USA). Sequencing-grade modified trypsin was purchased from Promega (Madison, WI, USA), and PCT microtubes were purchased from Pressure BioSciences, Inc. (South Easton, MA). HPLC-grade acetonitrile was purchased from Burdick and Jackson (Muskegon, MI, USA). Water was purified using a Milli Q system (Millipore, Molsheim, France).

Conventional Ovemight Digestion. To perform protein digestion, $100 \mu \mathrm{g}$ of each standard protein ( $\alpha$-lactalbumin, alcohol dehydrogenase I, fructose-bisphosphate aldolase A) was dissolved in $50 \mathrm{mM}$ of ammonium bicarbonate $(\mathrm{pH} 8.0)$ to a final concentration of $1 \mu \mathrm{g} / \mu \mathrm{L}$. If it is necessary the proteins were denatured in $8 \mathrm{M}$ urea. The samples were reduced with $10 \mathrm{mM}$ DTT at $37^{\circ} \mathrm{C}$ for $30 \mathrm{~min}$. IAA was added to a final concentration of $20 \mathrm{mM}$, and the resulting mixture was incubated at $37^{\circ} \mathrm{C}$ in the dark for $30 \mathrm{~min}$. The mixture was diluted 5-fold with 50 $\mathrm{mM}$ of ammonium bicarbonate ( $\mathrm{pH} 8.0$ ), trypsin (1:50 proteaseto-protein ratio) was added, and the mixture was incubated overnight at $37^{\circ} \mathrm{C}$.

PCT-Assisted Digestion. Sample preparation for pressureassisted digestion was the same as for the conventional overnight digestion except for the following additional steps. Prior to tryptic digestion, the protein solution mixture with trypsin was transferred to the PCT microtube. Each sample was incubated at 25,37 , and $50{ }^{\circ} \mathrm{C}$ for $60 \mathrm{~min}$ using PCT at $20 \mathrm{kpsi}$. Briefly, pressure cycling was performed at the indicated pressure for 60 cycles. Each $60 \mathrm{~s}$ pressure cycle consisted of $50 \mathrm{~s}$ at high pressure and $10 \mathrm{~s}$ at atmospheric pressure.

Digestion of Stem Cell Proteomes. For the complex protein mixture analysis, proteins of $16 \mu \mathrm{g} / 100 \mu \mathrm{L}$ from human mesenchymal stem cells (hMSC) were equally subjected to overnight digestion at $37{ }^{\circ} \mathrm{C}$ for $16 \mathrm{~h}$, to PCT-assisted digestion at $25^{\circ} \mathrm{C}$ for $1 \mathrm{~h}$, and non-PCT-assisted digestion at $25^{\circ} \mathrm{C}$ for $1 \mathrm{~h}$. hMSCs were isolated from human bone marrow aspirate. Cells were culture-expanded in dulbecco's modified eagle medium supplemented with $10 \%$ fetal bovine serum, $100 \mathrm{U}$ penicillin, $100 \mathrm{mg} /$ $\mathrm{mL}$ streptomycin (Invitrogen, Carlsbad, CA, USA), and $10 \mathrm{ng} /$ $\mathrm{mL}$ basic fibroblast growth factor (Sigma-Aldrich). The Institutional Review Board of Ajou University Medical Center (Su- won, Korea) approved this study. A detailed description of protein preparation can be found in the literature. ${ }^{20}$

LC- MS Analysis and Database Search. Peptides from standard protein mixture samples were analyzed using one dimensional liquid chromatography/tandem mass spectrometry (1DLC-MS/MS). Peptides were identified using MS/MS with a nano-LC-MS system consisting of a Surveyor HPLC system (ThermoFinnigan, USA) and a LTQFT mass spectrometer (ThermoFinnigan, USA) equipped with a nano-electrospray source. An autosampler was used to load $5 \mu \mathrm{L}$ aliquots of the peptide solutions onto a $\mathrm{C}_{18}$ trap-column (i.d. $300 \mu \mathrm{M}$, length $5 \mathrm{~mm}$, and particle size $5 \mu \mathrm{m}$; Dionex). The peptides were desalted and concentrated on the column at a flow rate of $20 \mu \mathrm{L} / \mathrm{min}$. Then, the trapped peptides were back-flushed and separated on a 100mm home-made microcapillary column consisting of $\mathrm{C}_{18}$ (Aqua; particle size $3 \mu \mathrm{M})$ packed into $75-\mu \mathrm{M}$ silica tubing with an orifice i.d. of $6 \mu \mathrm{M}$.

The mobile phases, $\mathrm{A}$ and $\mathrm{B}$, were composed of 0 and $80 \%$ acetonitrile, respectively, and each contained $0.02 \%$ formic acid and $0.5 \%$ acetic acid. The LC gradient began with $5 \% \mathrm{~B}$ for 15 min and was ramped to $15 \%$ B over $5 \mathrm{~min}$, to $50 \%$ B over $70 \mathrm{~min}$, to $95 \%$ B over $5 \mathrm{~min}$, and remained at $95 \%$ B over 5 min and $5 \% \mathrm{~B}$ for another $5 \mathrm{~min}$. The column was re-equilibrated with $5 \% \mathrm{~B}$ for $15 \mathrm{~min}$ before the next run. The voltage applied to produce an electrospray was $2.2 \mathrm{kV}$. In each duty circle of mass analysis, one high-mass resolution $(100,000) \mathrm{MS}$ spectrum was acquired using the FT-ICR analyzer, followed by five datadependant MS/MS scans using the linear ion trap analyzer. For MS/MS analysis, normalized collision energy (35\%) was used throughout the collision-induced dissociation (CID) phase.

Stem cell proteome samples were analyzed using 2DLC-MS/ MS. A detailed description of 2DLC-MS/MS analysis can be found in the literature. ${ }^{4}$ Briefly, a strong cation exchange $(5 \mu \mathrm{M}$, $3 \mathrm{~cm}$ ) column was placed just before the $\mathrm{C}_{18}$ trap column. Peptide solutions were loaded in $20-\mu \mathrm{L}$ aliquots for each run. Peptides were displaced from the SCX phase to the $\mathrm{C}_{18}$ phase by a salt gradient that was introduced through an autosampler loop and then desalted for $10 \mathrm{~min}$ at a flow rate of $20 \mu \mathrm{L} / \mathrm{min}$. Then, the trapped peptides were separated on a home-made capillary $\mathrm{C}_{18}$ column, where the size of the column and gradient conditions were the same as those used in 1DLC-MS/MS analysis. A six-step salt gradient was performed using $2 \mu \mathrm{L}$ of 50,250 , and 500-mM ammonium acetate $(0.1 \%$ formic acid in water) and 3 and $5 \mu \mathrm{L}$ and $500-\mathrm{mM}$ ammonium acetate $(0.1 \%$ formic acid in $30 \% \mathrm{ACN}$ ).

Data Analysis. MS/MS spectral data were analyzed for identification using the following software analysis protocols. MS/ MS spectra were searched with in-house ProLucid software ${ }^{21}$ against the IPI Human protein database (released in May, 2009) concatenated to a decoy database in which the sequence for each entry in the original database was reversed. ProLucid was used with a monoisotopic mass selected, a precursor mass error of $5 \mathrm{ppm}$, and a fragment ion mass error of $1 \mathrm{Da}$. Full and half tryptic peptides were selected with one potential miscleavage. Carbamidomethylated cysteine was chosen as a fixed modification. Oxidized methionine, carbamylated lysine, and carbamylated N-terminus were chosen as variable modifications. The resulting spectral matches were assembled and filtered using 
DTASelect with a peptide false-positive rate of $1 \%$. The identified protein list includes single peptide hits. Protein identifications from a shared peptide were counted as a single protein.

\section{Results and Discussion}

\section{Comparison of PCT-Assisted Digestion and Conventional Ovemight Digestion from Standard Protein Mixture Analysis.} Recently, several fast enzymatic digestion methods have been introduced for high-throughput protein analysis. In this study, we used PCT to achieve fast enzymatic digestion. PCT studies were performed using a Barocycler instrument, which uses changes in pressure to manipulate the samples under analysis within a closed system. The effect of PCT on enzyme activity was previously studied under different conditions of pressure, pressing time, or in the presence of an organic solvent in buffer media for enzyme digestion. ${ }^{6}$ PCT efficiently enhanced enzyme activity in a short time of less than $1 \mathrm{~h}$. Lopez-ferrer reported that when pressure was applied to solutions that contained protein in the absence of trypsin, no protein degradation products were observed, indicating that the pressure treatment itself did not cause protein fragmentation. ${ }^{12}$

We examined the effect of PCT on enzyme activity at temperatures of 25,37 , and $50{ }^{\circ} \mathrm{C}$ and compared the results to the conventional method. For this experiment, a mixture of three proteins was used as a model protein mixture sample. Proteins were digested under $20 \mathrm{kpsi}$ using 60 differential pressure cycles for a total of $60 \mathrm{~min}$ at each temperature in the presence or absence of urea. Urea was used as a chaotrope to aid in protein denaturing.

Table 1 presents a comparison between PCT-assisted digestions at different temperatures based on protein sequence coverage. Similar or slightly improved sequence coverage was observed for all proteins in all PCT-assisted digestions compared with the conventional method. There was no significant difference between each temperature for PCT-assisted digestion, or between PCT-assisted 1-h digestion and conventional overnight digestion. In PCT-assisted digestion at 25 and $50{ }^{\circ} \mathrm{C}$, proteins were digested to the same extent as digestion at $37^{\circ} \mathrm{C}$, which is the typical temperature for trypsin digestion. However, in the presence of urea, most proteins showed improved sequence coverage in all experiments.

The total number of identified peptides, including miscleavages, showed the same trend as protein sequence coverage (Fig. 1); it was roughly similar for all experiments and increased in all digestions with urea.

A large number of miscleaved peptides were included in the digestion with urea. It is known that urea aids in denaturing proteins and allows enzymes to access the denatured proteins. However, the higher percentage of miscleaved peptides relative to total peptides shows that urea also decreased enzyme activity and caused incomplete protein digestion. Thus, for a more active enzyme digestion, it may be necessary to eliminate or reduce excess urea after protein denaturing occurs.

When urea was added to the protein solutions, there was an additional consideration. Urea in solution will equilibrate with ammonium cyanate, and isocyanic acid results in the carbamylation of free amine groups on the proteins and peptides. Figure 2 shows that the number of carbamylated peptides increased significantly with increasing temperature, accounting for $\sim 42 \%$ of peptides for PCT-assisted digestion with urea at $50{ }^{\circ} \mathrm{C} .^{22}$ Even when both methods were performed at $37^{\circ} \mathrm{C}$, a greater amount of carbamylated peptides was identified using conventional overnight digestion for $16 \mathrm{~h}$ compared with PCT-assisted digestion for $1 \mathrm{~h}$. The carbamylation of proteins and peptides increased with increasing temperature and longer reaction times.

Three MS/MS spectra of the peptides from PCT-assisted digestion at 25,37 and $50{ }^{\circ} \mathrm{C}$ are shown in Figure 3. These were identified as (a) non-modified, (b) N-terminal carbamylated, and (c) N-terminal and internal lysine carbamylated peptide of ILDKVGINYWLAHK (Fig. 3) by ProLucid search. For the carbamylated peptides, the characteristic fragment ion appears to result from the molecular ions due to a loss of carbamyl group (CONH). They also showed mass difference of corresponding b ions by carbamylation $(\Delta 43)$.

Carbamylation is detrimental to protein characterization because it often occurs on the side chains of lysine residues, rendering a protein unsuitable for trypsin digestion. Moreover, even if the carbamylation does not prevent tryptic digestion, ${ }^{23}$ it will often confound the results with peptides that have unexpected masses. ${ }^{24}$ Thus, carbamylation can mislead protein identification in proteomics.

We selected PCT-assisted digestion at $25^{\circ} \mathrm{C}$ with urea as an optimized method for fast protein digestion to simultaneously maximize protein sequence coverage and the number of identified peptides and to minimize the production of carbamylated peptides.

Application to Complex Protein Mixtures Using Shotgun Proteomics. We applied this method for fast protein digestion to a proteomic sample. A proteome extract from a preparation of human mesenchymal stem cells was separated into three identical aliquots. The first was subjected to PCT-assisted digestion at $20 \mathrm{kpsi}$ for 60 cycles during $60 \mathrm{~min}$ at $25^{\circ} \mathrm{C}$, and the second and third aliquots were subjected to a trypsin digestion following

Table 1. Protein sequence coverage (\%) for PCT-assisted digestion at different temperatures compared to conventional overnight digestion

\begin{tabular}{|c|c|c|c|c|c|c|c|c|}
\hline & \multicolumn{2}{|c|}{ PCT 1 h $25^{\circ} \mathrm{C}$} & \multicolumn{2}{|c|}{ PCT 1 h $37^{\circ} \mathrm{C}$} & \multicolumn{2}{|c|}{ PCT $1 \mathrm{~h} 50{ }^{\circ} \mathrm{C}$} & \multicolumn{2}{|c|}{ Conv. overnight $37^{\circ} \mathrm{C}$} \\
\hline & w/o urea & with urea & w/o urea & with urea & w/o urea & with urea & w/o urea & with urea \\
\hline$\alpha$-Lactalbumin & $86.60^{a}$ & 86.60 & 84.50 & 86.60 & 84.50 & 86.60 & 75.40 & 82.17 \\
\hline Alcohol dehydrogenase I & 71.77 & 84.85 & 63.10 & 72.90 & 64.07 & 75.40 & 64.47 & 67.80 \\
\hline Fructose-bisphosphate aldolase A & 84.23 & 99.20 & 78.73 & 93.60 & 78.03 & 98.43 & 71.70 & 88.80 \\
\hline
\end{tabular}

${ }^{a}$ Each protein sequence coverage is an average of triplicate LC-MS analyses. 


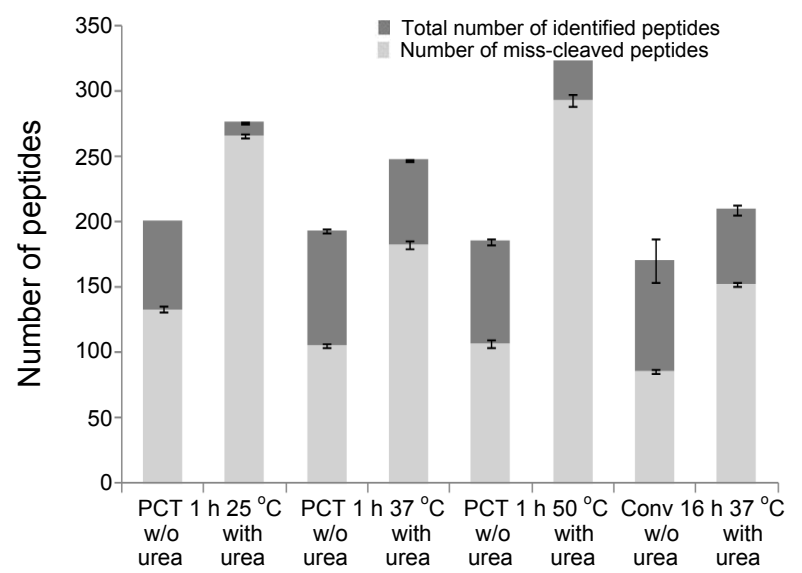

Figure 1. PCT-assisted digestion compared to conventional overnight digestion for a standard protein mixture. The histogram shows the total number of identified peptides, including miscleaved peptides. PCTassisted digestion was performed at 25,37 , and $50{ }^{\circ} \mathrm{C}$ for $1 \mathrm{~h}$ with or without urea. Each number is an average of triplicate LC-MS analysis.

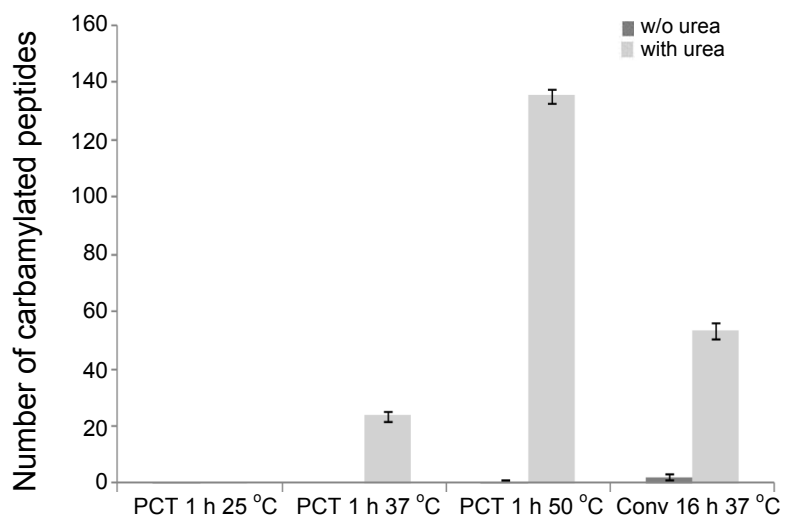

Figure 2. Histograms show the number of carbamylated peptides from each analysis. Each number is an average of triplicate LC-MS analysis.

(a)

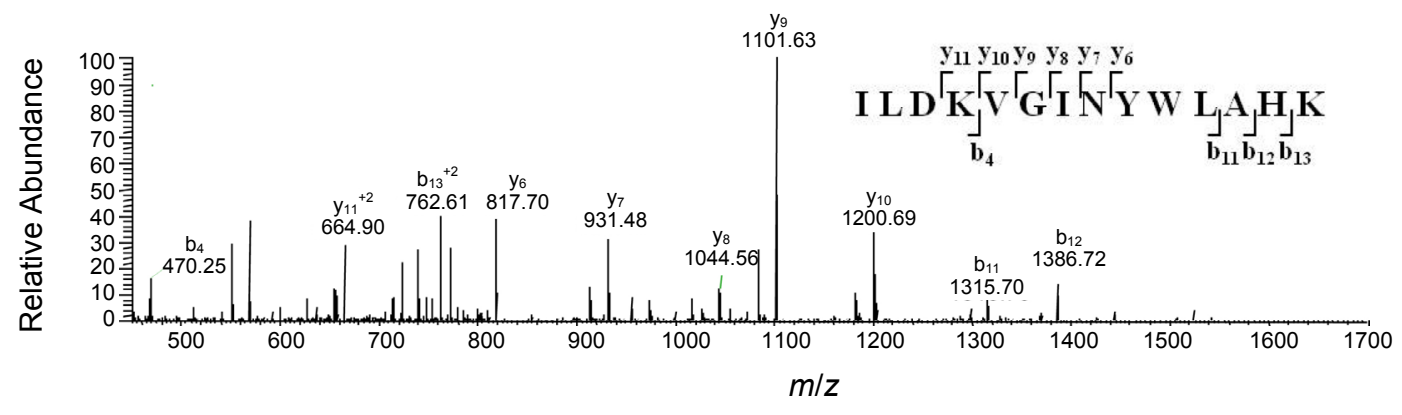

(b)

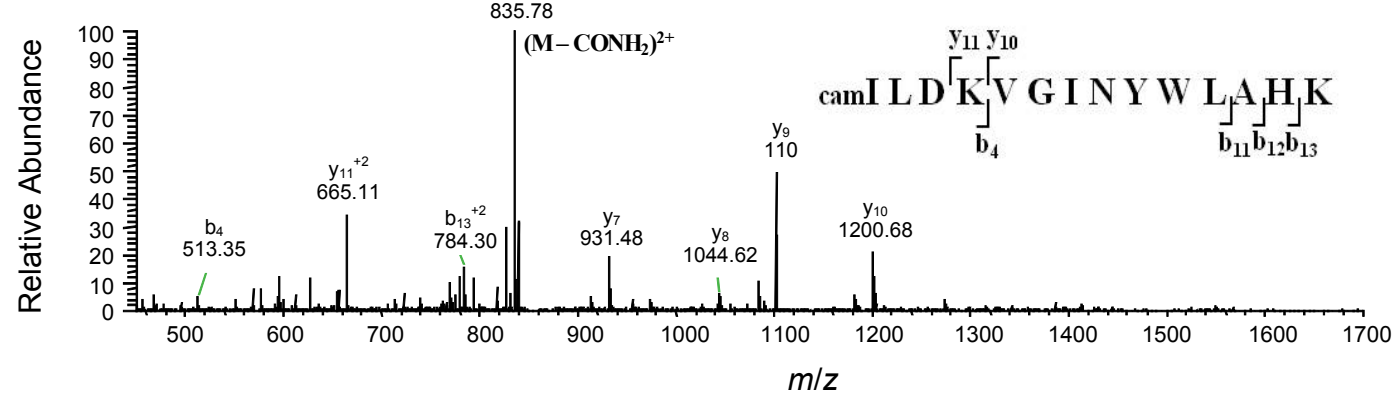

(c)

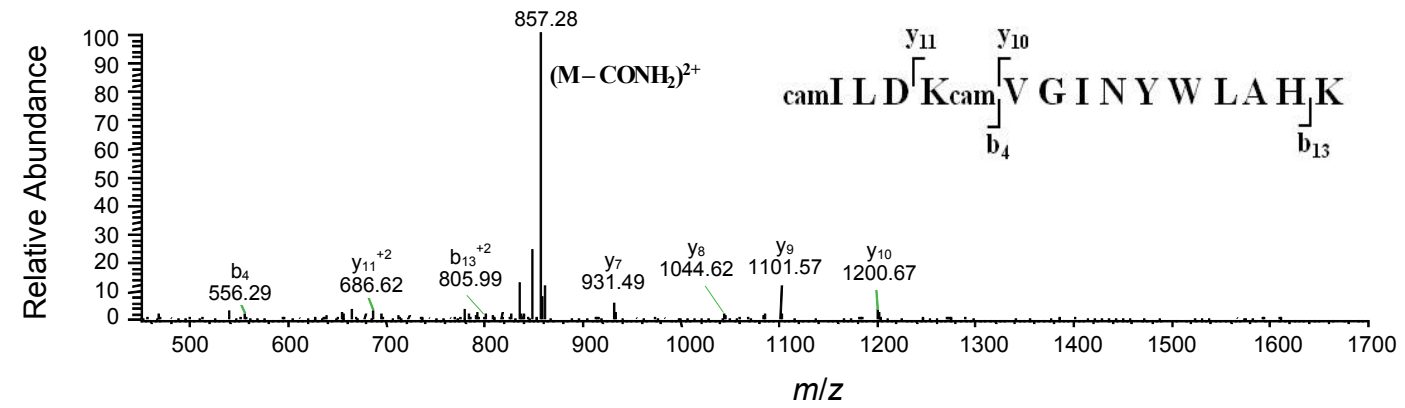

Figure 3. MS/MS spectra of peptide ILDKVGINYWLAHK (a), N-terminal carbamylated peptide camILDKVGINYWLAHK (b), and N-terminal and internal lysine carbamylated peptide ${ }_{\text {cam }} \mathrm{ILDK}_{\text {cam }}$ VGINYWLAHK (c). They were resulted from PCT-assisted digestion at 25,37 , and $50{ }^{\circ} \mathrm{C}$, respectively.

the conventional overnight method at $37{ }^{\circ} \mathrm{C}$ and non-PCTassisted 1-h digestion at $25^{\circ} \mathrm{C}$ for comparison.

The digested peptide mixtures were analyzed using 2 DLC-
MS/MS. Figure 4 (a) shows that the total number of identified peptides obtained using PCT was similar to that obtained using conventional digestion. However, only $23 \%$ of the peptides were 
(a)

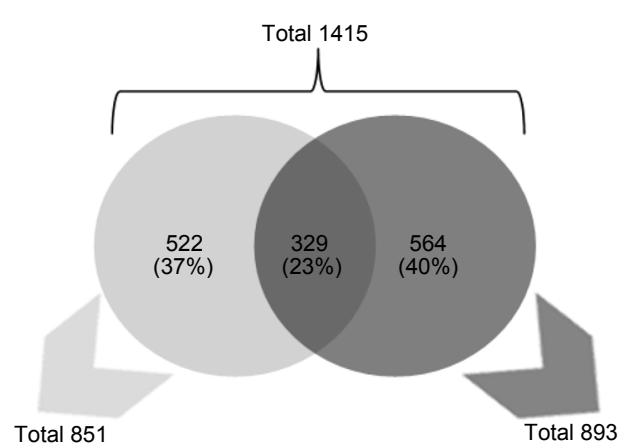

Conv overnight $37^{\circ} \mathrm{C}$

PCT $1 \mathrm{~h} 25^{\circ} \mathrm{C}$

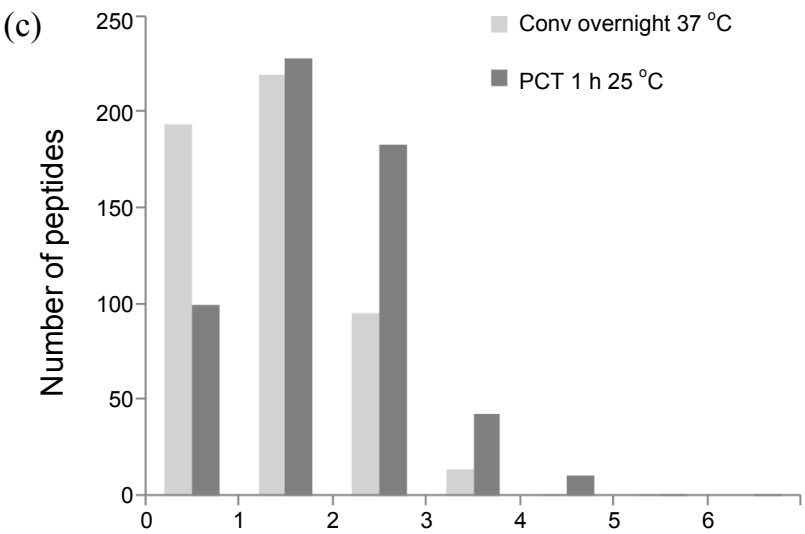

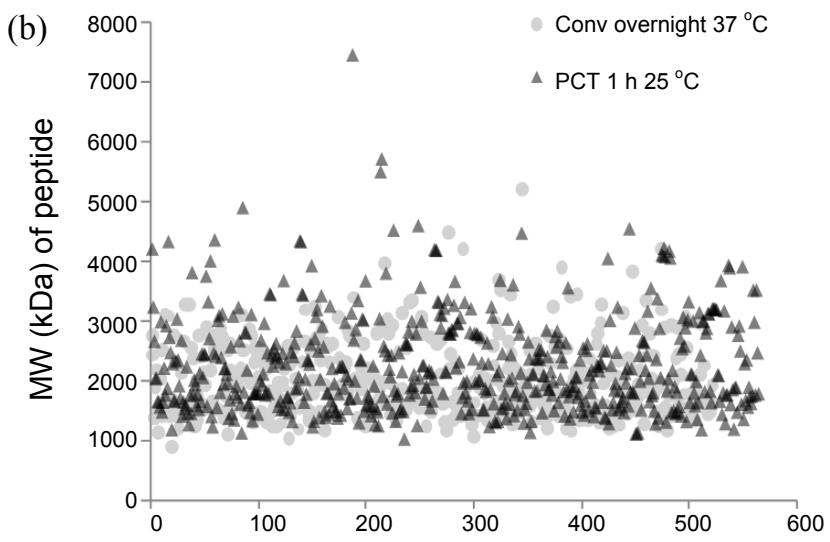

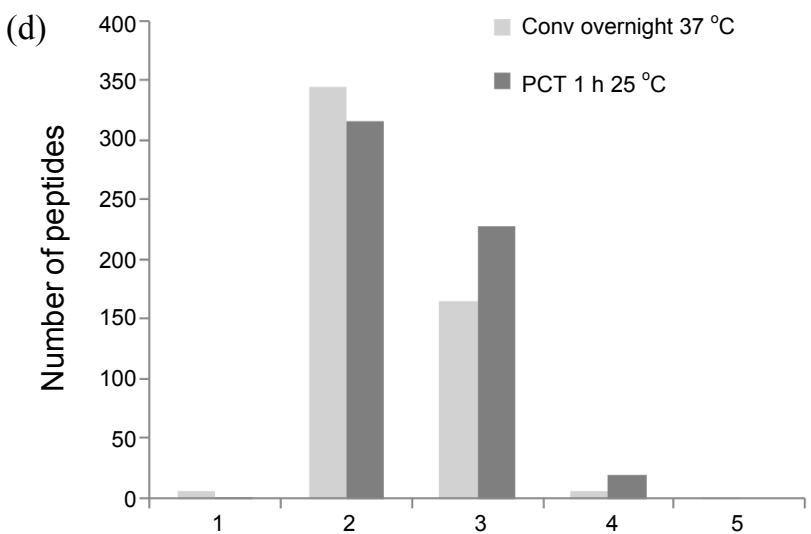

Figure 4. PCT-assisted digestion compared to conventional overnight digestion from proteome analysis of human mesenchymal stem cells. (a) Overlap between the identified peptides. (b) Molecular weight distribution of unique peptides identified in each analysis. (c) Number of identified peptides with miscleavages. (d) Charge distribution of unique peptides identified in each analysis.

(a)

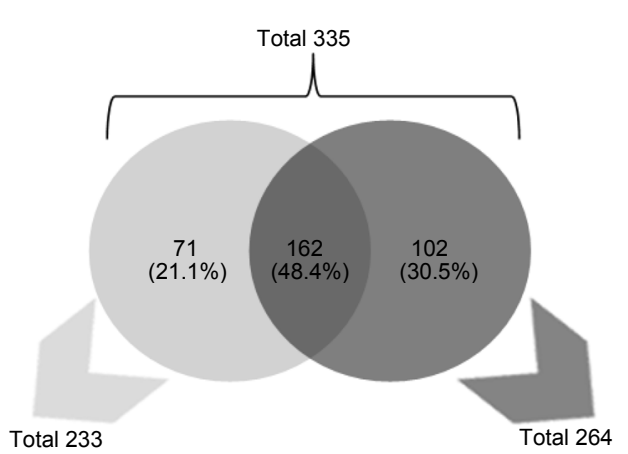

Conv overnight $37^{\circ} \mathrm{C}$

PCT 1 h $25^{\circ} \mathrm{C}$ (b)

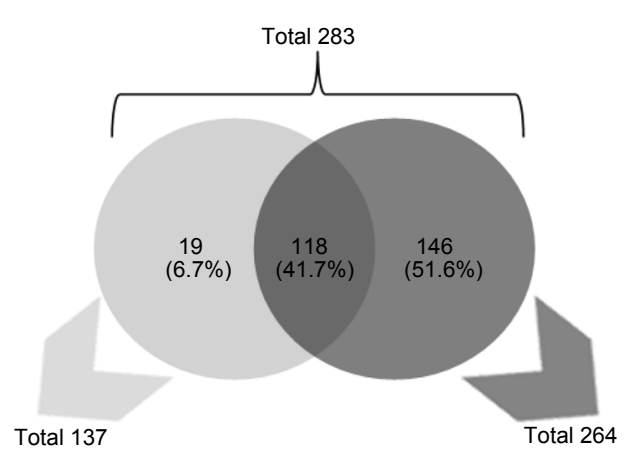

Non-PCT 1 h $25^{\circ} \mathrm{C}$

Figure 5. Overlap between the identified proteins from proteome analysis of human mesenchymal stem cells (a) Conventional overnight digestion versus PCT-assisted digestion. (b) non-PCT 1-h digestion versus PCT-assisted 1-h digestion.

commonly identified in both analyses. We examined which peptides were uniquely identified using each digestion method. Figure 4 (b) and (c) represent the distributions of unique peptides identified from each analysis with respect to molecular weight (MW) and the number of miscleavage sites. The number of peptides with miscleavage sites was low for the conventional digestion, while more than $82.4 \%$ of the PCT-assisted digestion had at least one miscleavage. The average MW of peptides obtained from PCT-assisted digestion was 2,244 Da. It was $\sim 200$
Da higher than 2030 Da from conventional digestion. Thus, more peptides were identified by ions with a higher charge using PCT-assisted digestion (Fig. 4 (d)). The average mass-to-charge ratios were 898 and 1015 for PCT digestion and conventional digestion, respectively. Peptide precursor ions with lower massto-charge ratios would provide MS/MS spectra with low collision energy. ${ }^{25}$

At the protein level, 162 of 335 proteins were commonly identified (Fig. 5(a)). Protein sequence coverage was slightly 
higher in PCT-assisted digestion (Supplementary Table S1); however, it is difficult to predict which proteins would be better digested using PCT-assisted digestion. Protein sequence coverage was different for each method, for various reasons, such as the extent of protein denaturing under given conditions, the number of enzyme active sites in a protein, and the duration of the enzymatic digestion.

A comparison of PCT-assisted digestion and non-PCTassisted digestion for $1 \mathrm{~h}$ at $25{ }^{\circ} \mathrm{C}$ showed that the former was more efficient than the latter for trypsin digestion. Figure 5(b) shows that $51.6 \%$ more proteins were identified using PCTassisted digestion than with non-PCT-assisted digestion under the same experimental conditions. Thus, PCT increases the probability of enzymes gaining access to proteins and produces more digested peptides.

\section{Conclusions}

We examined the effectiveness of PCT during enzyme digestion and compared the results to conventional overnight digestion. Varying the temperature did not significantly change the protein sequence coverage or the number of identified peptides. Improved results were obtained when urea was added to the digestion. However, many carbamylated peptides were included in the PCT-assisted digestion at $50{ }^{\circ} \mathrm{C}$. The carbamylation of proteins and peptides increased with increasing temperature and longer reaction times. PCT-assisted digestion with urea for $1 \mathrm{~h}$ at $25^{\circ} \mathrm{C}$ identified 264 proteins from a stem cell proteome sample and was more effective than non-PCT 1-h digestion with urea and showed the acquisition of results comparable to those obtained using conventional overnight digestion, but in a much shorter time frame. These results suggest that PCT enhanced the probability enzymes gaining access to proteins and improved protein identification with shorter analysis times.

Acknowledgments. This work was supported by KBSI research grant (G30121) and the Converging Research Center Program through the Ministry of Education, Science and Technology (2010K001115).

\section{References}

1. Blackler, A. R.; Klammer, A. A.; MacCoss, M. J.; Wu, C. C. Anal.
Chem. 2006, 78, 1337

2. Denison, C.; Rudner, A. D.; Gerber, S. A.; Bakalarski, C. E.; Moazed, D.; Gygi, S. P. Mol. Cell. Proteomics 2005, 4, 246.

3. Hu, Q.; Noll, R. J.; Li, H.; Makarov, A.; Hardman, M.; Graham, C. R. J. Mass. Spectrom. 2005, 40, 430.

4. Washburn, M. P.; Wolters, D.; Yates, J. R. Nat. Biotechnol. 2001, 19, 242.

5. Hernandez, P.; Muller, M.; Appel, R. D. Mass. Spectrom. Rev. 2006, 25, 235.

6. Lopez-Ferrer, D.; Petritis, K.; Hixson, K. K.; Heibeck, T. H.; Moore, R. J.; Belov, M. E.; Camp II, D. G; Smith, R. D. J. Proteome. Res. 2008, 7, 3276

7. Rabilloud, T.; Adessi, C.; Giraudel, A.; Lunardi, J. Electrophoresis 1997, 18, 307.

8. McCarthy, J.; Hopwood, F.; Oxley, D.; Laver, M.; Castagna, A.; Righetti, R. G.; Williams, K.; Herbert, B. J. Proteome. Res. 2003, $2,239$.

9. Hervey, W. J. T.; Strader, M. B.; Hurst, G. B. J. Proteome. Res. 2007, 6, 3054.

10. Blonder, J.; Chan, K. C.; Issaq, H. J.; Veenstra, T. D. Nat. Protoc. 2006, 1,2784

11. Zhong, H.; Zhang, Y.; Wen, Z.; Li, L. Nat. Biotechnol. 2004, 22 , 1291.

12. Lopez-Ferrer, D.; Capelo, J. L.; Vazquez, J. J. Proteome. Res. 2005, 4, 1569

13. Pramanik, B. N.; Mirza, U. A.; Ing, Y. H.; Liu, Y. H.; Bartner, P. L.; Weber, P. C.; Bose, A. K. Protein Sci. 2002, 11, 2676.

14. Sun, W.; Gao, S.; Wang, L.; Chen, Y.; Wu, S.; Wang, X.; Zheng, D.; Gao, Y. Mol. Cell. Proteomics 2006, 5, 769 .

15. Chicon, R.; Belloque, J.; Recio, I.; Lopez-Fandino, R. J. Dairy Res. 2006, 73, 121 .

16. Meersman, F.; Dobson, C. M.; Heremans, K. Chem. Soc. Rev. 2006, 35, 908 .

17. Ringham, H.; Bell, R. L.; Smejkal, G. B.; Behnke, J.; Witzmann, F. A. Electrophoresis 2007, 28, 1022

18. Belloque, J.; Chicon, R.; Lopez-Fandino, R. J. Agric. Food Chem. 2007, 55, 5282.

19. Yang, H.-J.; Hong, J.; Lee, S.; Shin, S.; Kim, J.; Kim, J. Rapid Commun. Mass Spectrom. 2010, 24, 901.

20. Kim, S. S.; Choi, J. M.; Kim, J. W.; Ham, D. S.; Ghil, S. H.; Kim, M. K.; Kim-Kwon, Y.; Hong, S. Y.; Ahn, S. C.; Kim, S. U.; Lee, Y. D.; Kim, H. S. Neuroreport 2005, 16, 1357.

21. Carvalho, P. C.; Xu, T.; Han, X.; Cociorva, D.; Barbosa, V. C.; Yates, J. R. Mol. Cell. Proteomics 2006, 5, S174.

22. Lippincott, J.; Apostol, L. Anal. Biochem. 1999, 267, 57.

23. Tagwerker, C.; Flick, K.; Cui, M.; Guerrero, C.; Dou, Y.; Auer, B.; Baldi, P.; Huang, L.; Kaiser, P. Mol. Cell. Proteomics 2006, 5, 737.

24. Klammer, A. A.; MacCoss, M. J. J. Proteome. Res. 2006, 5, 695.

25. Rogalski, J. C.; Lin, M. S.; Sniatynski, M. J.; Taylor, T. J.; Youhnovski, N.; Przybylski, M.; Kast, J. J. Am. Soc. Mass. Spectrom. 2005, 16, 505 . 